\title{
Pigmented Macula on the Gingival Papillain a Young Male: Diagnosis and Management: A Case Report
}

Esteves $C^{1}$, Guimares $L^{2}$ and Migliari $D^{1 *}$

${ }^{1}$ Department of Stomatology, School of Dentistry,

University of Sao Paulo, Brazil

${ }^{2}$ Department of Stomatology, Section of Oral Pathology, School of Dentistry, University of Sao Paulo, Brazil

*Corresponding author: Dante Migliari, Universidade de São Paulo Faculdade de Odontologia, Departamento de Estomatologia, Disciplina de Estomatologia Clínica Av. Prof. Lineu Prestes, 2227, Cidade Universitária São Paulo, SP -Brazil

Received: December 08, 2016; Accepted: J anuary 14, 2017; Published: January 17, 2017

\section{Introduction}

Physiologic melanin pigmentation is by far the most common darkened spot on the oral mucosa. They are easily and mainly recognizable by a diffuse pigmentation on the attached gingiva, predominantly seeing in dark-skinned individual orlight-skinned black individuals $[1,2]$.

On the other hand, an isolated pigmented spot on the oral mucosa usually rings an alert signal. Although oral pigmented-related malignancy, represented by melanoma, is quite rare a lesion in the oral mucosa, the presence of an isolated pigmented lisianthus sitegets clinicians aware of a possible oral melanoma [3].

This article describes a case of a tiny, pigmented spot of the gingival papilla that, otherwise, was necessary to exclude malignancy.

\section{Case Presentation}

A 13-year-old white male was referred to our clinic for evaluation of small spot that had recently appeared on his gingiva. The patient's parents were concerned about the nature of the lesion since the dentist that initially examined the patient had said that a biopsy would be necessary for a proper diagnosis. Clinically, there was a slightly raised, rounded shape lesion of brown color, with a smooth surface, measuring about $4 \mathrm{~mm}$ in diameter, on gingival papilla (Figure 1A). This was the only lesion seen in the oral mucosa; the patient had numerous philipson his skin-face. Apart from this, the patient was healthy.

The clinical diagnosis was of pigmented nevus vs.melanocytic macula. An excisional biopsy was taken, and the histopathologic result was of a melatonin macula (Figure $2 \mathrm{~A}$ and B). A light scar was noticed after 3 weeks following surgery (Figure 1B).

\section{Discussion}

Melanotic macula appears to occur most predominantly on the vermilion border of the lower lip, occurring mostly ( 82 to $92 \%$ of the cases)in Caucasian individuals aging 40 years old or older $[4,5]$. Lesions are small, usually measuring less than $1 \mathrm{~cm}$ in diameter, ranging from brown to deep black in color. Melanotic lesions are harmless -excisional biopsy is only indicated as to differentiate it from melanoma and (most frequently) for cosmetic reason. Histopathology shows normal number and morphology of melanocytes and increase amount of melanin [1].

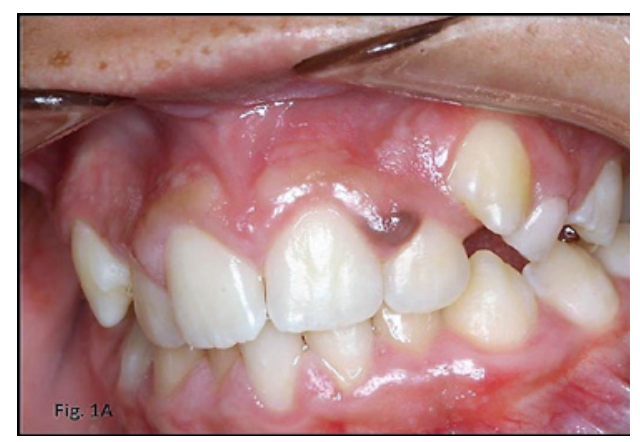

Figure 1A: Clinical pictures: a brown rounded papule (seemingly harmless) is shown on the gingival papilla. Multiple ephelis spots can be seen scattered on skin area of the lip.

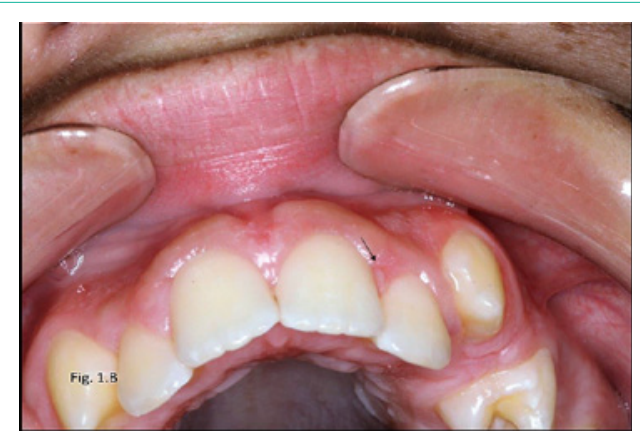

Figure 1B: A small scar had resulted from the excisional biopsy.
Austin J Dent - Volume 4 Issue 1 - 2017

ISSN : 2381-9189 | www.austinpublishing group.com

Migliari et al. (C) All rights are reserved
Citation: Esteves C, Guimares L and Migliari D. Pigmented Macula on the Gingival Papillain a Young Male: Diagnosis and Management: A Case Report. Austin J Dent. 2017; 4(1): 1061. 


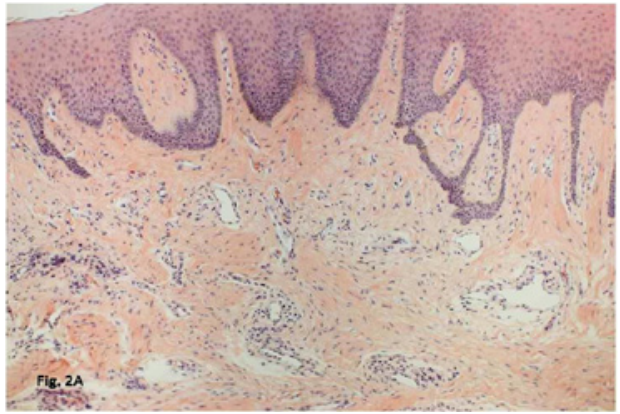

Figure 2A: Histopathologic section: magnification 10x, shows an epithelia with hyperkeratosis and melanin pigment in the basal-cell layer.

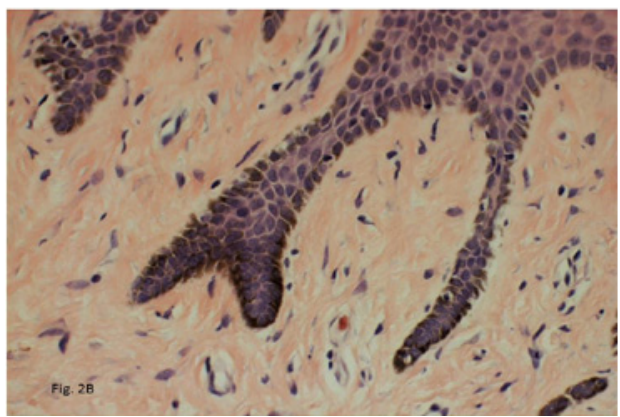

Figure 2B: The pigment could also be seen freely in the lamina propria or intracellularly within melanophages (magnification 40x).

Apart from the unusual location (gingival papilla) and the patient's age (very much below the average age for the occurrence of melanotic lesion) in the present case, the main question raised was the necessity to perform a biopsy. The reason for the intervention was more concerned with the patient's parents' anxiety about an effective diagnosis of the lesion rather than any suspicion of malignity. Therefore, this was the main reason for excising the lesion. Additionally, there was also an aesthetic concern for the patient. This, however, could be solved by applying liquid nitrogen over the lesion, using a cotton swab [2]. The drawback of this procedure is the lack of histopathological examination. Therefore, a conventional surgery had plenty advantage, although a small scar has arisen after healing.
Although ephelis and melanotic macula share a similarity on histologic appearance [3], there is no clinical relationship between them. It may tempt to say that the coexistence of ephelides in this case could be an indication of a genetic factor causing the appearance of both lesions. But this is just a mere speculation.

Other lesions that may share clinical similarity and possibly taken as clinical differential diagnoses are melanoacanthoma, blue nevus, post inflammatory pigmentation, and vascular lesion, apart from the other two already mentioned (pigmented nevus and melanotic macula). Either melanoacanthoma or blue nevus are possible diagnosis, although they are more commonly seen on the buccal and hard-palate mucosae, respectively, affecting adult individuals [1,2]. Post inflammatory pigmentation is mostly observed in association with oral lichen plan us and could be ruled out, as well as vascular lesion, such as hemangioma, which usually appears at birth or during the neonatal period and blanches on digital pressure [1].

Finally, there is no standard approach for an isolated pigmented lesion on the oral mucosa [4,5]. A clinician may be able to persuade a patient that most of isolated pigmented lesions on the oral mucosa have a benign behavior and only need to be checked on a regular basis. But most clinicians - and patients alike - usually prefer the lesion being excised to undergoing a long term follow-up, as this has been regarded the best-effective measure for avoiding any possible malignant development.

\section{References}

1. Kauzman A, Pavone M, Blanas N,Bradley G. Pigmented Lesions of the Oral Cavity: Review, Differential Diagnosis, and Case Presentations. J Can Dent Assoc. 2004; 70: 682-683.

2. Eisen D.Disorders of Pigmentation in the Oral Cavity. ClinDermatol. 2000 18: $579-587$.

3. Chin-Jyh Y. Cryosurgery treatment of melanin pigmented gingiva. (Oral Surg Oral Med Oral ) Pathol Radiol Endod. 1998; 86: 660-663.

4. Buchner A, Hansen LS. Melanotic macule of the oral mucosa. A clinicopathologic study of 105 cases. Oral Surg Oral Med Oral Pathol. 1979; 48: 244-249.

5. Page LR, Corio RL, Crawford BE, Giansanti JS, Weathers DR. The oral melanotic macule. Oral Surg Oral Med Oral Pathol. 1977; 44: 219-226.
Austin J Dent - Volume 4 Issue 1 - 2017

ISSN : 2381-9189 | www.austinpublishinggroup.com

Migliari et al. (C) All rights are reserved
Citation: Esteves C, Guimares L and Migliari D. Pigmented Macula on the Gingival Papillain a Young Male: Diagnosis and Management: A Case Report. Austin J Dent. 2017; 4(1): 1061. 